\title{
Research on error detection technology of numerical control machine tool
}

\author{
Cao YongJie \\ Shanghai University of Engineering Science ,Shanghai ,china, 200437 \\ E-mai:I donallove@163.com
}

Keywords: Laser interferometer; CCD laser displacement sensors; Eddy current displacement sensor

\begin{abstract}
Research on the errors recognition and measurement technology for the Numerical Control machine tools based on laser testing technology is the main content of this paper..In this paper,Renishaw laser interferometer and high accuracy displacement sensors are used to measure the positioning errors and thermal errors of the spindle in the machine tools. This measurement would be widly used in the mechanical industry.Bedises, it's very useful in improving machine tools cutting precisions.
\end{abstract}

\section{Introduction}

The machining accuracy of NC machine tools is a direct cause of the machining accuracy of the workpiece, the final machining accuracy of the workpiece is determined by the relative displacement error between the machine tool and the workpiece. Due to the influence of various errors of machine tools, the relative displacement between the cutting tool and the workpiece is very difficult to be equal to zero. Therefore, in order to reduce the relative displacement between the cutting tool and the workpiece, improve the machining accuracy of the machine tool, it must analyze and research the error of the machining accuracy.

\section{Source of error}

The general CNC machine or CNC machine tool mainly consists of bed, column, spindle and various linear guide rail or a rotating shaft. Every part of it will produce errors. The processing error sources of $\mathrm{NC}$ machine tool in the following aspects: (1)produced in the manufacturing and assembly parts and structure of machine tool geometric error, including parts size error and assembly error; (2) machine tool II internal and external heat source caused by the thermal deformation error; (3)the deadweight of the machine tool, cutting force deformation and the vibration error due to the insufficient rigidity has; (4) produced by the machine tool axis servo system servo tracking error; (5) the NC interpolation algorithm of interpolation error; (6)the other errors, such as external vibration, humidity, air change generated environment error and detection system detection error[1][2] [9].

There are two kinds of errors, which can be divided into categories: the accuracy of machine tool machining, and the error in the process of machine tools.

Quasi static error refers to the error which is closely related to the manufacturing accuracy of the machine tool, and the machine tool's accuracy in a certain period of time. It includes geometric error, motion error, thermal distortion and error caused by the weight of machine tool. The relationship between the error sources and their influence factors are shown in Figure 1. 


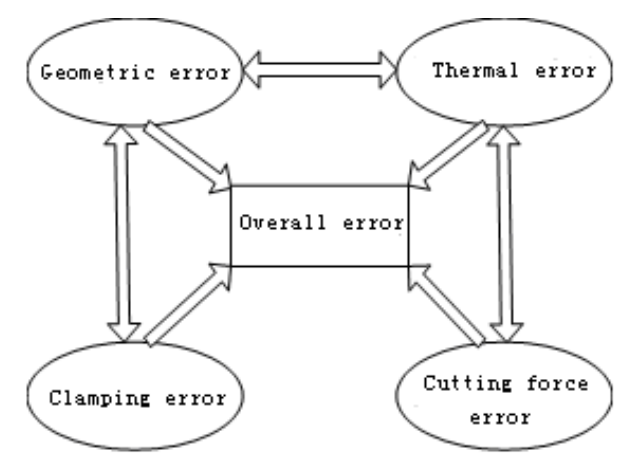

Fig. 1 Main error source of machine tool and its influence factors

The characteristics of dynamic error is more complex, it can be caused by the following reasons: the main axis motion error, machine vibration, servo control error, etc., to reduce the error of the machine tool itself to be transformed.

The main error sources of NC machine tools are studied by E.K.Kline and 1990 in the, and they are divided into three parts, such as machine tools, machining process and detection. The proportion of all kinds of errors is shown in Table 1.

Table 1 The proportion of the error sources of NC machine tools

\begin{tabular}{|c|c|c|c|}
\hline \multirow{3}{*}{ Error of machine tool } & Geometric error & $22 \%$ & \multirow{3}{*}{$50 \%$} \\
\hline \multirow{3}{*}{ Process error } & Thermal error & $28 \%$ & \\
\cline { 2 - 3 } & Cutting tool error & $13.5 \%$ & \\
\cline { 2 - 3 } & Fixture error & $7.5 \%$ & \multirow{3}{*}{$35 \%$} \\
\cline { 2 - 3 } & Thermal error of workpiece & $6.5 \%$ & \\
\cline { 2 - 3 } & Operating error & $7.5 \%$ & \\
\hline Detection error & & & $15 \%$ \\
\hline
\end{tabular}

From the above table, we can see that the numerical control machine tools, the error source, the geometric error and thermal error of the largest proportion. Therefore, this paper will focus on the detection of these two kinds of errors.

\section{Geometric error detection of numerical control machine tool}

The geometric error mainly comes from the manufacture of machine tools, the matching error between machine parts and the movement of the machine tool. It mainly includes the straightness errors and angular motion error for screw pitch change and the positioning error, because rail deformation caused by, because screw, gear, reverse clearance and servo drive system of loses moves and produces the reverse clearance error, and a servo mismatch error. The geometric error is related to the position of the tool or the workpiece.

For the three axis space coordinate system, if an object is moving along a certain axis, its movement has six degrees of freedom (as shown in Figure 2), then there are six geometric error components, that is, the straightness error of the three axis and the rotation error of the three axis. So for three axis NC machine tool, three axis motion there were 18 error component, together with three axes between still exist the verticality error, a total of 21 error component [3]. In which, the linear positioning accuracy and positioning accuracy of $\mathrm{CNC}$ machine tools is the most important two indicators of geometric error, and the commonly used detection equipment is laser interferometer, this paper uses RENISHAW laser interferometer to detect the machine tool, as shown in Figure 3, the measurement data is shown in Figure $4^{[4]}$. 


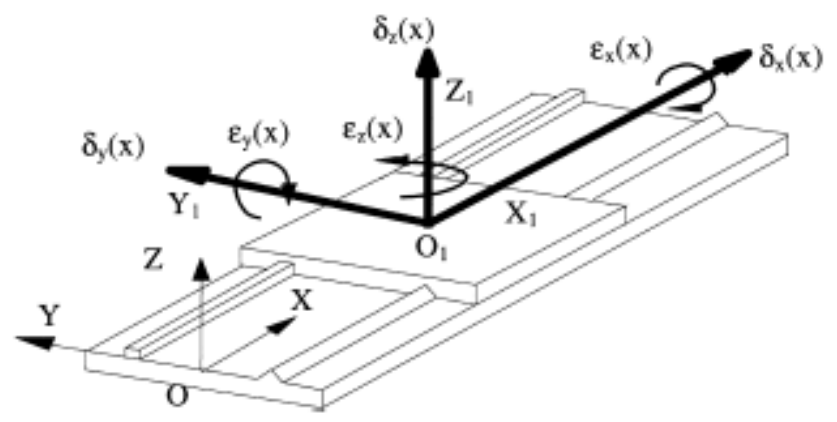

Fig. 26 errors in the direction of the $\mathrm{X}$ axis
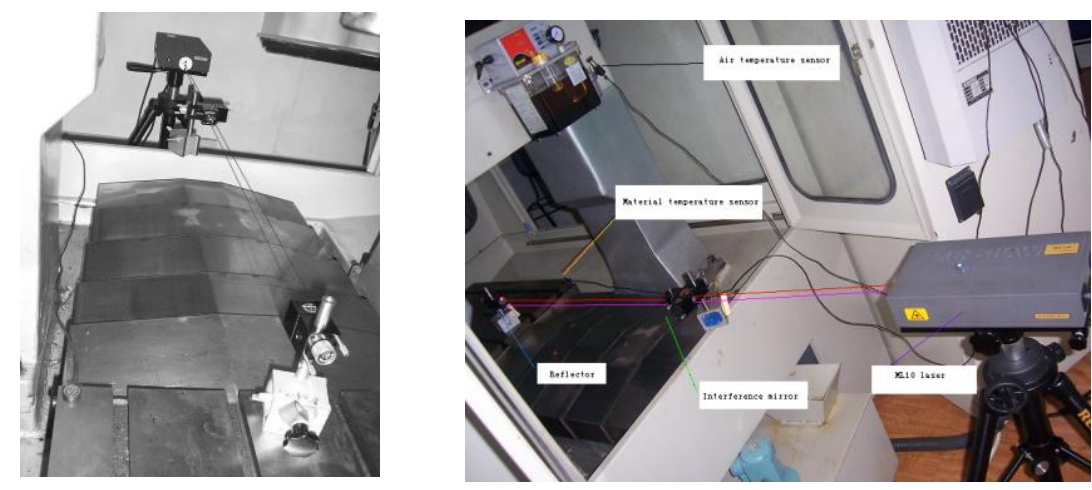

Fig. 3 Linear error measurement

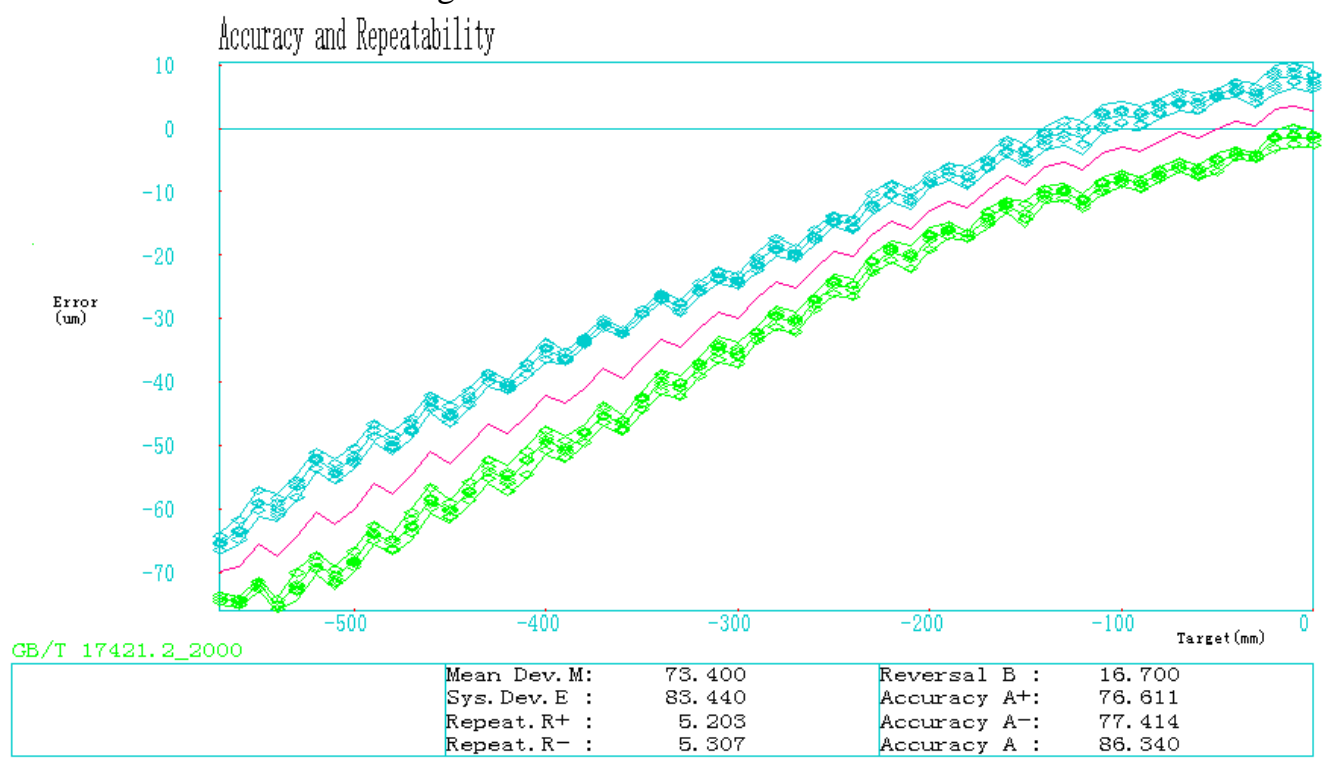

Fig. 4 Linear error data graph

\section{Thermal error of NC machine tool}

The thermal error of machine tool is mainly due to the complicated temperature field caused by the machine tool's work. The system is disturbed by internal and external heat sources, so that the temperature of the machine parts can be changed to the unstable stage of the thermal equilibrium and the thermal deformation of the machining precision is reduced.

Thermal error of the machine tool is divided into two categories: (1), and is independent of the location of the thermal error, such as thermal drift of the machine tool spindle and slide; (2), and is related to the location of the thermal error, such as because of changes in the temperature field changes caused by scale expansion and screw pitch pitch error, resulting in changes along with the temperature field of positioning error; machine tool thermal deformation also cause the machine axis perpendicularity between the change, resulting in Perpendicularity Error; machine tool uneven 
heating will guide rail deformation resulting in random bed temperature field change caused by the straightness errors and angular motion error.

For three axis vertical NC machine tools, thermal error is mainly caused by the thermal expansion of the main shaft, the thermal deformation of the spindle box, the thermal expansion of the XYZ shaft screw or the thermal deformation of the column and the thermal deformation of the column(As shown in Figure 5). Among them, there are 14 the thermal error elements associated with the temperature ${ }^{[5][6]}$ [7].

(1) Move side coordinates $\mathrm{X}, \mathrm{Y}, \mathrm{Z}$ zero respectively in three directions of thermal drift is $\delta_{x x 0}(\mathrm{t}) 、 \delta_{y x 0}(\mathrm{t}) 、 \delta_{z x 0}(\mathrm{t}), \delta_{x y 0}(\mathrm{t}) 、 \delta_{y y 0}(\mathrm{t}) 、 \delta_{z y 0}(\mathrm{t}) 、 \delta_{x z 0}(\mathrm{t}) 、 \delta_{y z 0}(\mathrm{t}) 、 \delta_{z z 0}(\mathrm{t})$. In which: the subscript first letters indicate the direction of the error; the second letter indicates the direction of the nominal movement; 0 indicates the thermal drift of zero.

(2) The main axis of the coordinate system of the $\mathrm{X}, \mathrm{Y}, \mathrm{Z}$ axis of the deflection of the Zero drift is $\delta_{x 0}(t), \delta_{y 0}(t), \delta_{z 0}(t)$.

(3) The main axis of the coordinate system of the $\mathrm{X}, \mathrm{Y}$ axis of the deflection of the hot tilt is $\theta_{\text {xs }}(\mathrm{t}) 、 \theta_{\text {ys }}(\mathrm{t})$.

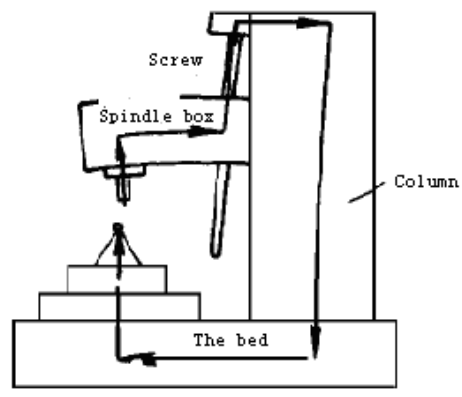

Fig. 5 Three axis vertical numerical control machine tool thermal deformation

In this paper, the thermal error measuring system of the $\mathrm{NC}$ machine tool is composed of three high precision displacement sensors, including two CCD laser displacement sensor (LK-150H) and one eddy current displacement sensor (EV-110V). Thermal deformation of machine tool spindle is shown in figure 6. Two CCD laser displacement sensors were placed in parallel with the machine tool $\mathrm{X}$ and $\mathrm{Y}$ directions, and the eddy current displacement sensor was fixed at the bottom of the aluminum rod (parallel to the $\mathrm{Z}$ direction of the machine tool). The main axis of the $\mathrm{NC}$ machine tool was $2000 \mathrm{rpm}$ and 5000rpm respectively. The time of each measurement is 7 hours, the first 5.5 hours of the spindle rotation, every 1 minutes to record a numerical, 1.5 hours after the machine tool, every 1 minutes to record a numerical. The thermal deformation under the spindle speed of 2000RPM and 5000RPM are shown in Figure 7 .
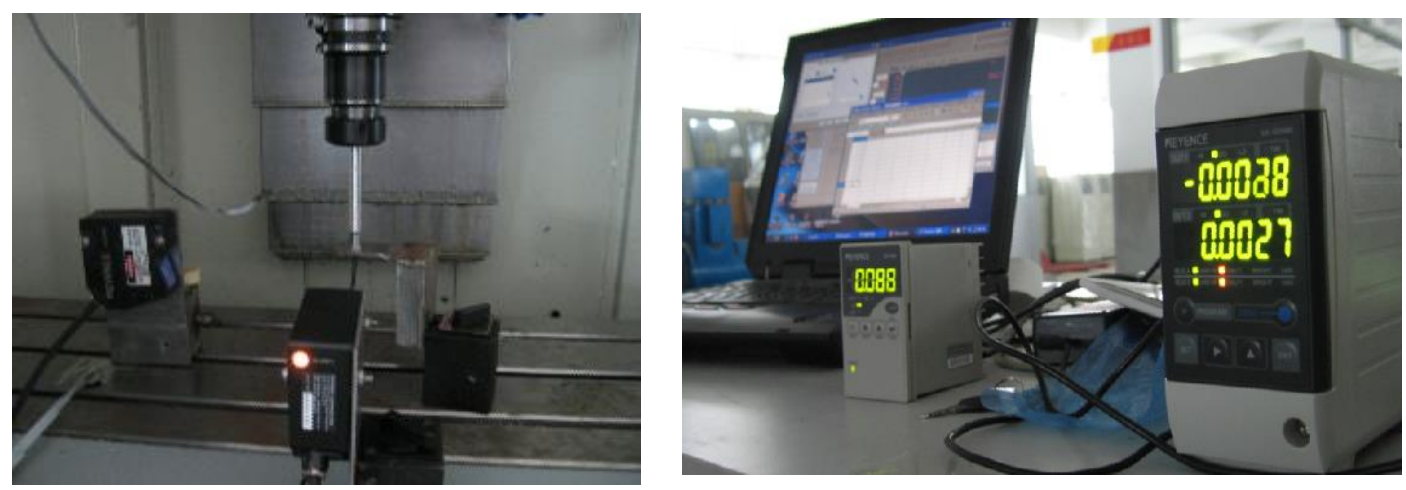

Fig. 6 Thermal deformation of spindle 

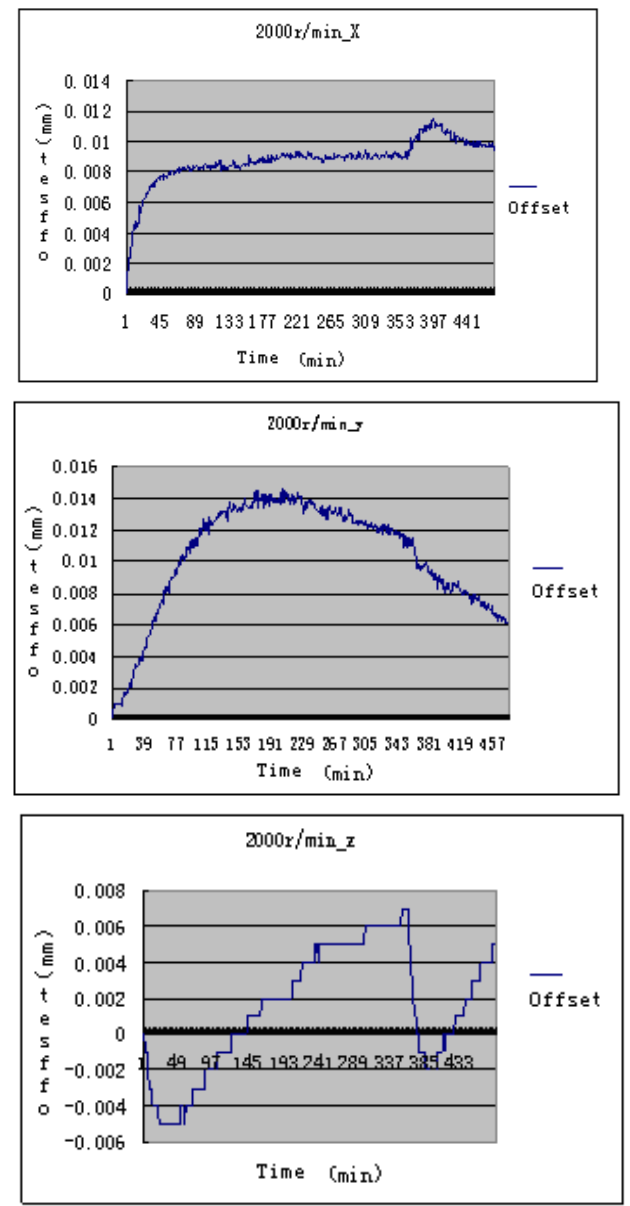

(a) $2000 \mathrm{rpm}$
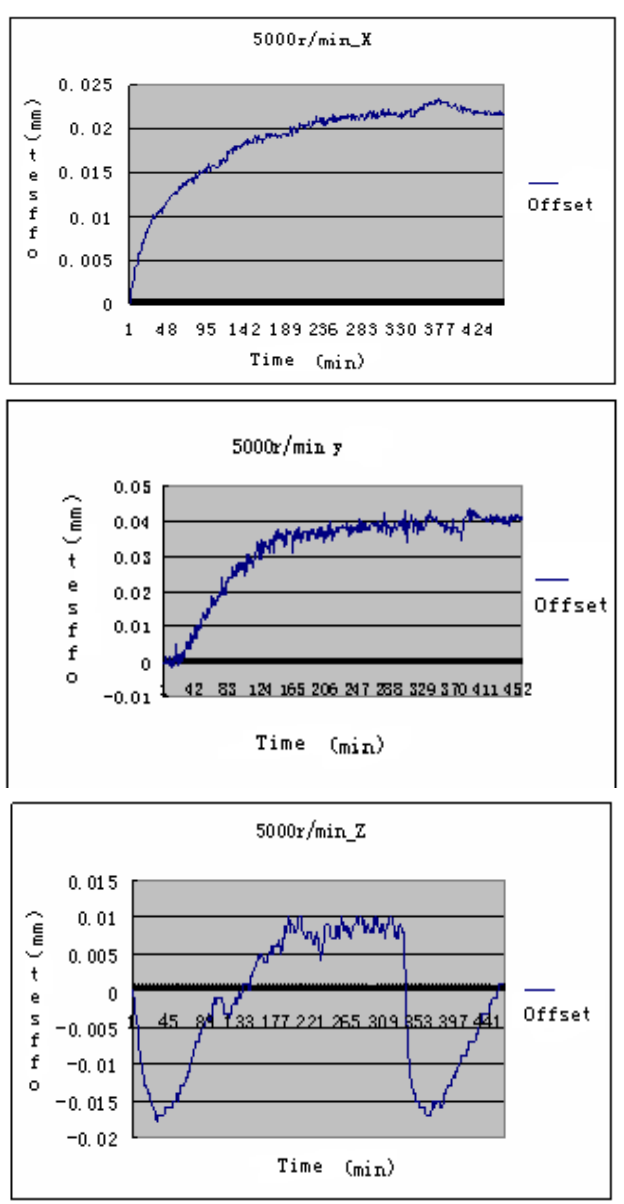

(b) $5000 \mathrm{rpm}$

Fig. $7 \mathrm{X}, \mathrm{Y}, \mathrm{Z}$ three directions hot deformation map

\section{Summary}

In this paper, the linear positioning error and thermal error of the spindle are measured by using Renishaw laser interferometer and high precision displacement sensor. In this paper, the error detection method is widely used in the research of machine tool industry, and it has important significance to further improve the machining accuracy of NC machine tools.

\section{References}

[1] Drouet P, Dubowsky S, Zeghloul S, Mavroidis C (2002) Compensation of geometric and elastic errors in large manipulators with an application to a high accuracy medical system. Robotica 20:341-352.

[2] Poonyapak P, Hayes MJD (2006) Towards a Predictive Model for Temperature-Induced Deformation of an Industrial Robot Proc of EuCoMeS the first European Conf. on Mechanism Science,Obergurgl (Austria)

[3] Brosed F, Santolaria J, Aguilar J, Guillom AD (2012) Laser triangu-Lation sensor and six axes anthropomorphic robot manipulator model-ling for the measurement of complex geometry products Robot.Comput Integr Manuf 28:660-671

[4] Xie SQ, Cheng D, Wong S, Haemmerle E (2008) Three-dimensional object recognition system for enhancing the intelligence of a KUKArobot. Int J Adv Manuf Technol 38(7-8):822-839 